\title{
Excessive Weight Loss Following Laparoscopic Gastric Mini Bypass or Roux-En-Y Gastric Bypass Surgery
}

\author{
Abdolreza Pazouki', Sima Karbalaei Esmaeili ${ }^{*}$ \\ ${ }^{1}$ Assistant Professor, Minimally Invasive Surgery Research Center, Iran University of Medical Sciences, \\ Tehran, Iran \\ ${ }^{2}$ Surgery Resident, Iran University of Medical Sciences, Tehran, Iran \\ Email: "simaesmaeili90@gmail.com
}

Received 13 June 2016; accepted 8 July 2016; published 11 July 2016

Copyright (C) 2016 by authors and Scientific Research Publishing Inc.

This work is licensed under the Creative Commons Attribution International License (CC BY).

http://creativecommons.org/licenses/by/4.0/

c) (i) Open Access

\section{Abstract}

Background: More than 90 percent of obesity surgery is done using a laparoscope. This method is superior to open surgery and lead to fewer complications, shorter hospital stay and faster recovery. This study compared course of weight loss following laparoscopic Gastric Mini Bypass or Roux-En-Y Gastric Bypass surgery, after one year of follow up. Materials and Methods: This randomized clinical trial was conducted among obese patients admitted to Rasoul Akram Hospital Obesity Clinic, Half underwent laparoscopic Roux-En-Y Gastric Bypass and the rest were undergoing laparoscopic Mini Gastric Bypass. The amount of weight loss during the first year after surgery will be discussed. Results: In this study, 75 obese patients were studied. Most of the participants were female (82.7\%). Participants aged between 18 and 59 years old (average = $36.8 \pm 9.8$ y/o). Before the surgery, there was no significant difference in weight between the two groups. Excessive weight loss after one month, six months nine months and one year between the two groups was significant and was more in Mini Gastric Bypass $(p<0.05)$. Conclusion: Respecting the benefits of Mini Gastric Bypass compared to the Roux-En-Y Gastric Bypass technique, it is suggested for patients with morbid obesity.

\section{Keywords}

Morbid Obesity, Laparoscopic Mini Gastric Bypass, Laparoscopic Roux-En-Y Gastric Bypass

\footnotetext{
${ }^{*}$ Corresponding author.
}

How to cite this paper: Pazouki, A. and Esmaeili, S.K. (2016) Excessive Weight Loss Following Laparoscopic Gastric Mini Bypass or Roux-En-Y Gastric Bypass Surgery. International Journal of Clinical Medicine, 7, 445-449. 


\section{Introduction}

Obesity is defined as excessive weight and body fat due to environmental factors and individual genetic predisposition factors. According to the body mass index (BMI) categories, obesity defined as BMI more than to 30 $\mathrm{kg} / \mathrm{m}^{2}$ [1]. Obesity is not a disease of known cause, but several factors are involved in its formation. Genetic factors, internal secretions, psychological factors and environmental factors play important roles in causing obesity. Energy imbalance is the most important factor in weight gain and obesity.

Scientific studies approved weight loss surgery for patients with a BMI more than $35 \mathrm{~kg} / \mathrm{m}^{2}$. More than $90 \%$ of the obesity surgeries performed by laparoscopy which is preferred to open surgery: It leads to fewer complications, shorter hospital stay and faster recovery. Gastric bypass surgery by loop method was first done by Mason \& Itoh in 1960, then Griffin and his colleagues introduced the open technique of Roux-En-Y Gastric Bypass. In 1994, first laparoscopic gastric bypass was performed in America and now America's most common bariatric surgery is gastric bypass. The operation is usually done as Roux-en Y, stomach is approximately divided into two small areas (30 - 50 cc) and large (The remaining stomach) and food enter the small area. In mini gastric bypass the surgeon does not cut the small intestine. The smaller stomach is connected to the 150 to $200 \mathrm{~cm}$ of small intestine. This new bypass has fewer side effects than the old method and length of stay after surgery is less [2].

In mini gastric bypass surgery, duration of surgery is about 30 minutes and hospital stay between 1 to 3 days while in the method of Roux-En-Y Gastric Bypass, duration of surgery was more than an hour and length of stay in hospital is between 4 and 8 days [3] [4]. In this study, candidate for bypass surgery referred to obesity clinic of Rasoul Akram Hospital during year 2013-2014, were randomly divided into two groups and one group underwent Roux-En-Y Gastric Bypass and the second group Mini Gastric Bypass and the difference between the two groups were studied.

\section{Material and Methods}

In this study, all patients with obesity who were referred to the obesity clinic since March 2013 to March 2014 in Rasoul Akram Hospital were enrolled. Half of the group was randomized to undergo laparoscopic Roux-En-Y Gastric Bypass and the rest undergone a Laparoscopic Mini Gastric Bypass. In both groups, the duration of surgery based on the minutes and weight loss over a year after surgery were recorded in kilograms. In this study, a researcher-made questionnaire was used for data collection. All questionnaires have been completed based on direct interviews with patients or relatives of patients who had full information of the patient's condition. Exclusion criteria included patients not wanting to participate in the study, lack of access to follow-up the patient's health status during follow-up, any severe illness in which surgery or anesthesia was impossible for the patient, mental instability and inability to understand the procedure, drug and alcohol addiction and eating disorders. SPSS software was used for data analysis and the results of the P-Value less than 0.05 significantly was considered.

\section{Results}

In this study, 75 patients with obesity who underwent surgery by one of the mini-gastric bypass or Roux-En-Y Gastric Bypass were studied. 62 participants were female (82.7\%). Participants were between 18 and 59 years old and the average age of the participants was $36.8 \pm 9.8$. Before the surgery, there was no significant difference between weights in two groups (Table 1). The weight loss between the two groups based on Independent Samples Test is shown in Table 2. The weight loss after 10 days and three months did not differ significantly between groups while weight loss after one month, after six months, after 9 months and one year was significantly higher in the mini gastric bypass group than the other group (Table 2). Duration of surgery in mini gastric bypass surgery significantly was less than the other group (Figure 1).

\section{Discussion}

Gastric bypass surgery was more common in the late 1990s. Effects of gastric bypass surgery are actually a combination of stomach volume reduction and mal-absorption of nutrients. This applies especially in people who consume large quantities of sweets and simple carbs and do not respond to bonding. Bypass surgery was more effective than bonding so that $60 \%$ to $70 \%$ of patients lose their excessive weight in 9 to 14 months after surgery. Studies have shown that mini gastric bypass was effective for the treatment of obesity and favorable 


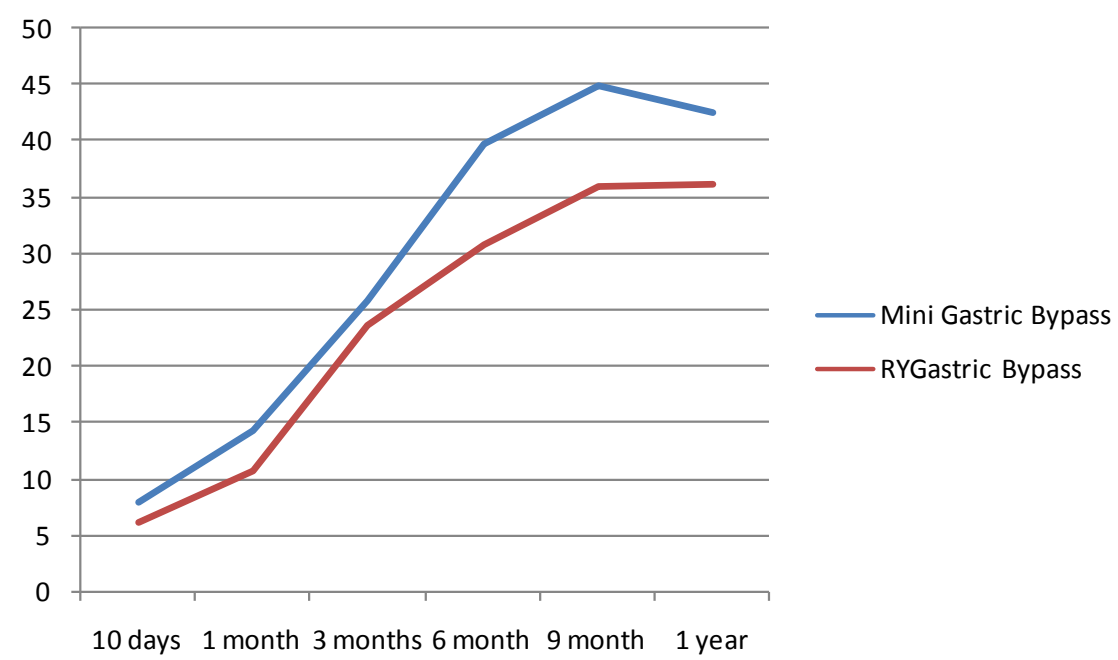

Figure 1. Weight loss (kg) after surgery.

Table 1. Weight and duration of surgery in two groups.

\begin{tabular}{cccccc}
\hline & & Min & Max & Mean & SD \\
Weight & Mini Gastric Bypass & 83 & 227 & 129.28 & 25.662 \\
& Roux-En-Y Gastric Bypass & 93 & 146 & 121.10 & 14.913 \\
Duration of & Mini Gastric Bypass & 60 & 160 & 101.97 & 24.204 \\
Operation & Roux-En-Y Gastric Bypass & 90 & 200 & 124.55 & 30.778 \\
\hline
\end{tabular}

Table 2. Mean weight loss (Kg) and mean excessive weight loss according to time in two groups.

\begin{tabular}{|c|c|c|c|c|c|c|c|}
\hline Weight Loss & Surgery & Mean (Kg) & SD & Sig. (2-tailed) & Mean (\%) & SD & Sig. (2-tailed) \\
\hline \multirow{2}{*}{10 days } & Mini Gastric Bypass & 7.98 & 3.578 & \multirow{2}{*}{0.056} & 18.867 & 19.7309 & \multirow{2}{*}{0.365} \\
\hline & Roux-En-Y Gastric Bypass & 6.26 & 2.261 & & 14.722 & 6.0903 & \\
\hline \multirow{2}{*}{1 Month } & Mini Gastric Bypass & 14.35 & 5.480 & \multirow{2}{*}{0.009} & 29.130 & 10.9085 & \multirow{2}{*}{0.426} \\
\hline & Roux-En-Y Gastric Bypass & 10.85 & 2.624 & & 26.596 & 11.9506 & \\
\hline \multirow{2}{*}{3 Month } & Mini Gastric Bypass & 25.75 & 9.084 & \multirow{2}{*}{0.040} & 54.436 & 29.7664 & \multirow{2}{*}{0.661} \\
\hline & Roux-En-Y Gastric Bypass & 23.82 & 7.295 & & 58.040 & 24.0787 & \\
\hline \multirow{2}{*}{6 Month } & Mini Gastric Bypass & 39.58 & 15.791 & \multirow{2}{*}{0.040} & 76.516 & 17.4284 & \multirow{2}{*}{0.499} \\
\hline & Roux-En-Y Gastric Bypass & 30.88 & 7.053 & & 71.011 & 24.3041 & \\
\hline \multirow{2}{*}{9 Month } & Mini Gastric Bypass & 44.83 & 11.036 & \multirow{2}{*}{0.032} & 93.246 & 22.2293 & \multirow{2}{*}{0.335} \\
\hline & Roux-En-Y Gastric Bypass & 35.96 & 7.781 & & 82.293 & 25.8923 & \\
\hline \multirow{2}{*}{$\begin{array}{l}\text { Weight loss } \\
\text { after one year }\end{array}$} & Mini Gastric Bypass & 42.55 & 25.809 & \multirow{2}{*}{0.095} & 93.600 & 5.0912 & \multirow{2}{*}{0.478} \\
\hline & Roux-En-Y Gastric Bypass & 36.23 & 10.693 & & 84.665 & 29.1695 & \\
\hline
\end{tabular}

results in the removal of diabetes type 2 in patients with obesity [5]-[8] and lead to improve the quality of life in these patients [9]. However mini gastric bypass is easier and safer procedure compared with Roux-En-Y Gastric Bypass in two-year follow-up period, any Achilles' heel for it has not been reported yet [10] [11]. Since the mini-gastric bypass in the stomach has not been cut and small intestine connected to 150 to $200 \mathrm{~cm}$ of small intestine, this method has fewer complications than the traditional Roux-En-Y Gastric Bypass [12], but the possibility of bile reflux in this method is higher than the conventional bypass method. In a study published in 2012, 1657 patients evaluated. Under the scheme, operation time and postoperative hospital stay and the rate of post- 
operative complications in patients with Roux-En-Y Gastric Bypass was more and weight loss in this group was less through a 5-year follow-up [12].

Excessive weight loss in mini gastric bypass after one year in our study was similar to other published studies [4]. In another study in 2008 on 16 patients under mini gastric bypass surgery results showed that patients had 78-minute surgery and postoperative hospital stay 1.2 days. There were no long-term complications and mortality after surgery and weight loss at two years after surgery was $72 \mathrm{~kg}$ [13]. Excessive weight loss in mini-gastric bypass surgery was reported as much as 70 percent in various studies over one [14] and 5 years [4] which was consistent with our results. Another study published in 2012 evaluated 1000 patients who had undergone mini gastric bypass surgery between 2005 and 2011 were studied. According to the study, mini gastric bypass was low-risk and effective method that can be performed easily and with little associated side effects. In this study, all patients had experienced reflux following surgery [15]. Previous studies have shown that mini gastric bypass surgery over the short-term, was safe and successful in excessive weight loss [16] [17], this point was confirmed in our study.

\section{Conclusion}

According to recent study and adapt these results with studies in other countries, mini gastric bypass seems to be the easier way than the Roux-En-Y Gastric Bypass, which is less time consuming procedures and hospital stays are shorter. Also, due to the lack of anastomosis between the stomach and the jejunum, is a safer way and the effects and duration of surgery and hospitalization is less than Roux-En-Y Gastric Bypass, to the extent effective in weight reduction for patients with obesity. The effect of this method in the treatment of obesity complications such as low back pain, sleep apnea, high blood pressure, diabetes and depression have been proven and so could act as a substitute, among bariatric surgery considered.

\section{Acknowledgements}

The authors need to thanks to the efforts of our hardworking colleagues in Minimally Invasive Surgery Research Center, who worked on the research process.

\section{References}

[1] Brunicardi, F., et al. (2014) Schwartz’s Principles of Surgery. 10th Edition, McGraw-Hill Education, New York.

[2] Bruzzi, M., et al. (2015) Single Anastomosis or Mini-Gastric Bypass: Long-Term Results and Quality of Life after a 5-Year Follow-Up. Surgery for Obesity and Related Diseases, 11, 321-326. http://dx.doi.org/10.1016/j.soard.2014.09.004

[3] Chakhtoura, G., et al. (2008) Primary Results of Laparoscopic Mini-Gastric Bypass in a French Obesity-Surgery Specialized University Hospital. Obesity Surgery, 18, 1130-1133. http://dx.doi.org/10.1007/s11695-008-9594-8

[4] Collins, B.J., et al. (2007) Gastric Bypass: Why Roux-en-Y? A Review of Experimental Data. Arch Surg, 142, 1000-1003; discussion 1004. http://dx.doi.org/10.1001/archsurg.142.10.1000

[5] Hu, X.G., et al. (2009) [Short-Term Outcome of Laparoscopic Gastric Bypass and Minigastric Bypass on Obesity Patients with Type 2 Diabetes Mellitus]. Zhonghua Wei Chang WaiKeZaZhi, 12, 554-557. (In Chinese)

[6] Kular, K.S., Manchanda, N. and Cheema, G.K. (2016) Seven Years of Mini-Gastric Bypass in Type II Diabetes Patients with a Body Mass Index $<35$ kg/m. Obesity Surgery, 26, 1457-1462.

[7] Lee, W.J., et al. (2005) Laparoscopic Roux-en-Y versus Mini-Gastric Bypass for the Treatment of Morbid Obesity: A Prospective Randomized Controlled Clinical Trial. Annals of Surgery, 242, 20-28.

http://dx.doi.org/10.1097/01.sla.0000167762.46568.98

[8] Lee, W.J., et al. (2012) Laparoscopic Roux-en-Y vs. Mini-Gastric Bypass for the Treatment of Morbid Obesity: A 10-Year Experience. Obesity Surgery, 22, 1827-1834. http://dx.doi.org/10.1007/s11695-012-0726-9

[9] Mini Gastric Bypass Surgery vs Gastric Bypass. http://www.ehow.com/facts 4842938 bypass-surgery-vs-gastric-bypass

[10] Mini Gastric Bypass. www.Surgery.com

[11] Musella, M., et al. (2016) Efficacy of Bariatric Surgery in Type 2 Diabetes Mellitus Remission: The Role of Mini Gastric Bypass/One Anastomosis Gastric Bypass and Sleeve Gastrectomy at 1 Year of Follow-Up. A European Survey. Obesity Surgery, 26, 933-940. 
[12] Noun, R., et al. (2007) Mini-Gastric Bypass by Mini-Laparotomy: A Cost-Effective Alternative in the Laparoscopic Era. Obesity Surgery, 17, 1482-1486. http://dx.doi.org/10.1007/s11695-008-9426-x

[13] Noun, R., et al. (2012) One Thousand Consecutive Mini-Gastric Bypass: Short- and Long-term Outcome. Obesity Surgery, 22, 697-703. http://dx.doi.org/10.1007/s11695-012-0618-z

[14] Parmar, C.D., et al. (2016) Mini Gastric Bypass: First Report of 125 Consecutive Cases from United Kingdom. Clinical Obesity, 6, 61-67. http://dx.doi.org/10.1111/cob.12124

[15] Peraglie, C.P. (2011) Laparoscopic Mini-Gastric Bypass in Patients 60 Years of Age and Older. Obesity Surgery, 21, 1023-1023.

[16] Rutledge, et al. (2005) Continued Excellent Results with the Mini-Gastric Bypass: Six-Year Study in 2,410 Patients. Vol. 15, New York, NY, ETATS-UNIS: Springer.

[17] Rutledge, R. (2007) Hospitalization before and after Mini-Gastric Bypass Surgery. International Journal of Surgery, 5, 35-40. http://dx.doi.org/10.1016/j.ijsu.2006.06.026

\section{Submit or recommend next manuscript to SCIRP and we will provide best service for you:}

Accepting pre-submission inquiries through Email, Facebook, Linkedin, Twitter, etc A wide selection of journals (inclusive of 9 subjects, more than 200 journals)

Providing a 24-hour high-quality service

User-friendly online submission system

Fair and swift peer-review system

Efficient typesetting and proofreading procedure

Display of the result of downloads and visits, as well as the number of cited articles

Maximum dissemination of your research work

Submit your manuscript at: http://papersubmission.scirp.org/ 